\title{
ESTERILIZACIÓN QUIRÚRGICA HUMANA Y LEGISLACIÓN ARGENTINA: ASPECTOS BIOMÉDICOS, JURÍDICOS Y ÉTICOS
}

\author{
Sergio Cecchetto*, Patricia Urbandt** y María Carla Bostiancic***
}

\begin{abstract}
Resumen: El Congreso argentino dictó recientemente la Ley 26.130-2006 sobre el régimen para las intervenciones de contracepción quirúrgica de varones y mujeres. Este documento revisa esta situación legislativa de este capítulo del ejercicio de la medicina en Argentina y el mundo y plantea observaciones críticas sobre su articulado, resaltando el derecho de las personas al acceso a otros métodos anticonceptivos no quirúrgicos; la conveniencia de que la pareja sexual del interesado conozca la decisión elegida; la necesidad de que se verifique la capacidad y la competencia de los candidatos, previo a la intervención quirúrgica por parte de un equipo profesional interdisciplinario; el deber de regular la situación por la que atraviesan las personas judicialmente incapacitadas; la oportunidad de fijar un tiempo prudente entre la información recibida y el consentimiento otorgado por el paciente; la obligación de que la esterilización no resulte la única práctica médica costeada por el sistema público de salud, las organizaciones de la seguridad social y las entidades de medicina prepaga, y sobre el alcance y la naturaleza de una objeción de conciencia que atienda a las circunstancias particulares de cada caso concreto.
\end{abstract}

Palabras clave: esterilización humana, legislación, bioética, Argentina

\section{HUMAN STERILIZATION SURGERY AND ARGENTINIAN LAW: BIOMEDICAL, LEGAL AND ETHICAL ASPECTS}

\begin{abstract}
Argentine's congress recently dictated the 26.130-2006 law about the procedure for sterilization surgery interventions in men and women. This work offers a review of the legal situation in Argentine and in the world. It points out critical observations to its items, highlighting the right to access to other non surgical contraceptive methods; the advisability for the interested sexual partner to know which decision was taken; the need to determine the competence of candidates prior to surgical intervention stated by an interdisciplinary professional team; the duty to regulate the special situation of legally incompetent persons; the importance of establishing an adequate time between the information and the patient's consent; to prevent sterilization to become the only medical practice paid by the public health system, social security organizations and prepaid medical entities; and to be careful about the reach and nature of conscientious objection in each specific circumstance.
\end{abstract}

Key words: Human sterilization, legislation, bioethics, Argentine

\section{ESTERILIZAÇÁO CIRÚRGICA HUMANA E A LEGISLAÇÁO ARGENTINA: ASPECTOS BIOMÉDICOS, JURÍDICOS E ÉTICOS}

\begin{abstract}
Resumo: O Congresso Argentino aprovou recentemente a Lei no. 26.130-2006 a respeito das intervençóes de contracepção cirúrgicas de homens e mulheres. Este trabalho oferece uma revisão d situação legislativa deste capítulo do exercício da medicina na Argentina e no mundo, apresentando os antecedentes das províncias e a recente lei nacional. Levanta observaçóes críticas sobre seu conteúdo, ressaltando o direito das pessoas ao acesso a outros métodos anticoncepcionais não cirúrgicos; a conveniência de que o casal sexual do interessado conheça a decisão eleita; a necessidade de que se verifique a capacidade e a competência dos candidatos, antes da intervenção cirúrgica por parte de uma equipe profissional interdisciplinar; o dever de regular a situaçáo especial que atravessam as pessoas judicialmente incapacitadas; a oportunidade de fixar um tempo prudente entre a informaçáo recebida e o consentimento outorgado pelo paciente; a obrigação ode que a esterilizaçáo não resulte como a única prática médica custeada pelo sistema pública de saúde, as organizaçôes de seguro social e as entidades de medicina de grupo e sobre o alcance e a natureza de uma objeção de consciência que atenda às circunstâncias particulares de cada caso concreto.
\end{abstract}

Palavras chave: esterilização humana, legislação, bioética, Argentina

* Doctor en Filosofía. Consejo Nacional de Investigaciones Científicas y Técnicas (CONICET), Universidad Nacional de Mar del Plata, Argentina

** Médico. Comité de Bioética de los Hospitales Interzonales General de Agudos "Dr. Oscar Alende" y Especializado Materno-Infantil "Victorio Tetamanti", Mar del Plata, Argentina

*** Abogada. Universidad Nacional de Mar del Plata, Argentina

Correspondencia: scypu@infovia.com.ar 


\section{La situación jurídica de la esterilización en Argentina y el mundo}

Desde 1945, declaraciones internacionales, legislación, jurisprudencia, decretos gubernamentales, reglamentaciones y normas ministeriales han afectado directamente las políticas sanitarias en materia de anticoncepción, aborto, enfermedades de transmisión sexual y esterilización humana, forzada o electiva, en cualquier parte del mundo. El ordenamiento legal resultante no ha considerado, en términos generales, las prácticas médicas esterilizantes y permanentes en el varón o la mujer como asunto punible. En algunos países, sin embargo, algunas disposiciones generales del derecho penal recogen consideraciones que podrían hacerse valer para juzgar tales prácticas como delitos. Por ejemplo, las legislaciones que echan mano de los sistemas consuetudinarios anglosajones suelen hablar de la esterilización permanente voluntaria como una forma particular de causarse un "daño corporal serio", de "agredirse" o "mutilarse criminalmente"; otras legislaciones influidas por el derecho civil francés se expresan en términos de "lesiones y heridas intencionales" orientadas a la mutilación, la amputación y privación de un miembro (...) u otra lesión permanente ${ }^{1}$. Estas ilustraciones de corte restrictivo han encontrado acogida en otros países centro y sudamericanos; sin embargo, la tendencia mundial es reemplazar las leyes limitativas por otras más abiertas y flexibles.

La confusión reinante respecto de la práctica en algunos países reside en la importancia concedida a la legislación penal en desmedro de ciertas leyes generales que rigen el desempeño de las profesiones médicas y demás actividades afines. Dos remedios se han propuesto para eludir estas dificultades: recurrir en cada oportunidad concreta a la justicia para elucidar la licitud o ilicitud del procedimiento, o promulgar leyes específicas que se ocupen a fondo de la temática, enumerando condiciones previas que los prestadores y los peticionantes deben cumplir. Con este último propósito, varios Estados introdujeron reformas en sus ordenamientos legales.

Las modificaciones registradas son de cuatro tipos: a) diseño de estatutos, reglamentaciones ministeriales, decisiones judiciales o decretos presidenciales, para permitir las prácticas con propósito de planificación familiar; b) ante la inexistencia de expresas normas

1 Esto no se aplica a las esterilizaciones permanentes ocasionadas por motivos terapéuticos. jurídicas restrictivas, se reconoce a la esterilización permanente como una práctica legal; c) se la denuncia como procedimiento punible si persigue una finalidad anticonceptiva o de planificación familiar, pero se la tolera si responde a razones terapéuticas o médicas o de salud; y d) no se explicita la legalidad de la esterilización permanente voluntaria(1).

Importa conocer ahora cuál es el actual panorama legal argentino respecto de la esterilización humana y cómo han influido en él las posiciones internacionales.

El Código Penal argentino, luego de establecer que comete un delito de lesiones aquel "...que causare a otro, en el cuerpo o en la salud, un daño que no esté previsto en otra disposición de este código" (artículo 89), califica como delito de lesiones gravísimas a las acciones que tienen como resultado la "pérdida de la capacidad de engendrar o concebir" (artículo 91). La discusión resulta así saldada por medio de una prohibición absoluta para que los médicos realicen este tipo de intervenciones.

Sobre otra órbita se movía hasta hace muy poco el Título II, Cap. I, artículo 20, inciso 18 de la Ley Nacional 17.132, que regulaba el ejercicio de la medicina y profesiones afines -con potestad sobre Capital Federal y ámbitos sometidos a jurisdicción nacional-, el cual impedía las intervenciones esterilizantes sin una indicación terapéutica perfectamente determinada y sin haber agotado todos los recursos tendientes a conservar los órganos reproductores. En su artículo 19, la misma ley especificaba que los profesionales de la medicina estaban obligados a "respetar la voluntad del paciente en cuanto sea negativa a tratarse o internarse (...). En las operaciones mutilantes se solicitará la conformidad por escrito del enfermo, salvo cuando la inconsciencia o la alienación o la gravedad del caso no admitiera dilaciones. En los casos de incapacidad, los profesionales requerirán la conformidad del representante del incapaz" (inciso 3). Es decir, la esterilización permanente sólo constituía delito cuando se realizaba sin fines terapéuticos, cuando la salud no reclamaba de manera imperativa y el cuerpo profesional determinaba cuáles eran esos casos excepcionales en los que se podía y debía intervenir. Pero, como la ley protege la integridad del paciente y su plena potestad para impedir una injerencia indebida, debía ser él mismo quien autorizara finalmente la práctica. Algunos pasajes del Código de Ética Médica de la Provincia de Buenos Aires rebajaban también la prohibición establecida en el Código Penal, 
pues, de existir una indicación médica adecuada y contando con el consentimiento informado del solicitante o de su representante, el equipo podía realizar la práctica. La ausencia de disposiciones específicas en muchos territorios del país hasta 2006, permitió que algunos se valieron de esta normativa para utilizarla por analogía en su propia área geográfica.

Ambas posiciones, la restrictiva del Código Penal o la más permisiva de la Ley 17.132 y del Código de Ética Médica bonaerense, mantienen un aire de familia, por cuanto sostienen una idea de indisponibilidad del cuerpo propio como telón de fondo de todas sus elucubraciones; en consecuencia, también consideran indisponibles a ciertos derechos y anotan alguna excepción exculpatoria (por ejemplo, la situación terapéutica o las condiciones de salud). Tanto la integridad física o corporal como la capacidad reproductiva entraban dentro de este rubro que debía ser protegido de manera absoluta, incluso contra la propia voluntad de los individuos afectados. Tales derechos indisponibles son ejercidos y disfrutados por el individuo; también él puede reclamar por su defensa, pero no en cambio atentar contra ellos so pena de caer en la indignidad. Esta dogmática clásica fue atacada en los últimos diez años con argumentos que van desde la denuncia del Estado como ente regulador de la vida personal, hasta su identificación como figura paternalista o, en su lugar, perfeccionista.

Aquellos que avalaron la versión más permisiva se preocuparon por saber si la indicación médica precisa y el consentimiento exigido bastaban por sí solos para desligar a los profesionales actuantes de una eventual responsabilidad futura por dańos. En este punto, la doctrina y la jurisprudencia se dividían. Un primer grupo entendía que sobre el cuerpo propio cada persona es soberana (artículos 19 y 75, inciso $22 \mathrm{de}$ la Constitución Nacional argentina). El límite de la autonomía personal en estos asuntos se presenta cuando se le infringe un daño a terceros, y la esterilización -según su entender- era una conducta autorreferente que atendía apenas a una idea personal de lo que es la excelencia y los ideales de vida buena. No era el Estado liberal, en cualquier caso, el que debía imponer ciertas valoraciones y jerarquías entre ideales de perfección (por ejemplo, la integridad y la salud por encima de la procreación, o viceversa), los cuales restringían la autorregulación de las personas. Un segundo grupo entendía útil la solicitud de una venia o autorización judicial previa a la instrumentación de la cirugía de esterilización, pues juzgaban la intromisión como asunto legítimo en tanto ésta quedaba limitada al reaseguro del peticionante y convalidaba y homologaba judicialmente lo ya acordado entre profesionales y candidatos a la cirugía. Esta pretensión ocasionó, a su vez, otro debate entre los juristas, porque se debió establecer si la justicia podía y debía entrometerse en cuestiones de estricto orden biomédico para disponer, autorizar $\mathrm{u}$ ordenar determinadas prácticas sobre las cuales no cuenta con competencia cognitiva alguna.

Sin embargo, sólo algunas de las solicitudes de esterilización permanente que recibían los efectores de salud respondían a una indicación terapéutica perfectamente determinada(2). Muchas otras incorporaban cuestiones psicológicas y componentes sociales que no podían subsumirse con facilidad dentro de una indicación médica estricta. Cuando estos requerimientos llegaban a los juzgados, frecuentemente por vía de amparo, cabía la posibilidad de que los magistrados se excusaran y desestimaran su participación en el asunto por motivos meramente formales, sin llegar a analizar la situación de fondo. La acción de amparo, pensaban, no se erige para lograr autorizaciones en favor de los pacientes ni de los facultativos, sino para que el juez conozca actos $\mathrm{u}$ omisiones que afectan derechos constitucionales reconocidos (ver Ley 7166 y Constitución de la Provincia de Buenos Aires, entre otras). Como resultado de ello, si existía indicación médica (lo que sea que se entienda por tal), los profesionales podían realizar dicha práctica sin necesidad de algún aval judicial extraordinario; en caso contrario, si esa indicación no existía, se incursionaba en el terreno de lo delictuoso y en esas circunstancias huelgan los oficios de un juez. Otros magistrados adoptaron una posición diferente: entendieron que la salud y el concepto médico de indicación podrían sufrir una ampliación que los llevara a abarcar no sólo aspectos biológicos físicos, sino también las esferas psicológica y social. Por tanto, al consentimiento informado del candidato y a la indicación médica ampliada -recogiendo información psicológica y social- había de sumárseles una venia judicial, con el fin de extremar el celo en resguardo de los intereses legítimos de los peticionantes y de la responsabilidad profesional de los expertos que intervendrían en la cirugía. 


\section{Legislación provincial y nacional en Argentina}

Esta diferencia de criterios en el área de la justicia repercutió negativamente en los equipos médicos. Ellos, casi sin excepción, consideraron a la esterilización humana permanente una materia riesgosa a la que resultaba conveniente no aproximarse. La vía legislativa fue la elegida en el último lustro en diversas provincias argentinas para disipar temores: Río Negro (Ley 3450-2000), Tierra del Fuego (Ley 533-2001), Chubut (Ley 49502002), Neuquén (Ley 2431-2003), La Pampa (Ley 2079-2003), Santa Fe (Ley 12323-2004), Chaco (Ley 5409-2004) y Mendoza (Ley 7456-2005). Todos estos territorios legislaron sobre la esterilización humana argumentando que no existían razones para limitar las libertades individuales (incluyendo la plena disposición del cuerpo propio en relación con la reproducción y los planes de vida personales y autorreferentes). Quedaba en entredicho, sin embargo, la competencia para legislar provincialmente sobre esta materia, por cuanto la permisibilidad de la esterilización permanente involucra, de suyo, una cuestión de fondo, objeto del Derecho Civil y, por tanto, competencia del Congreso de la Nación.

Un amplio movimiento social acompañó la redacción de cada una de esas normativas; no obstante, en líneas generales, en todas ellas se sobrepasó el marco dentro del cual se habían estado desarrollando los debates sobre salud reproductiva en el país. Los partidarios de la licitud de las intervenciones quirúrgicas esterilizantes en seres humanos se valieron de distintas justificaciones o situaciones de excepción para aceptar la práctica, pero no reconocieron sin más la libertad humana de disponer del cuerpo propio en función de un plan de vida personal y a la autonomía por encima de todo otro valor en juego. La intervención quirúrgica esterilizante podía realizarse-según el entendimiento de la mayoría- sólo cuando mediaba una justificación terapéutica, en razón de una imposibilidad de la mujer para tolerar un parto o por estrictos motivos de salud determinados por la esfera médica para la mujer o para el varón.

La jurisprudencia nacional, más audaz en este terreno, buscaba siempre establecer una indicación terapéutica certera como coartada para acceder a los deseos de los solicitantes, o bien echaba mano de una noción ampliada de salud para hacerlo. Ambos caminos suponían una visión ética perfeccionista - por cuanto imponían a los individuos ciertos valores o ideales hasta el punto de limitar su autodeterminación-o, al menos, una visión ética jurídico-paternalista, de carácter débil, pues decidían por los individuos qué era lo más conveniente para ellos y los protegían de sus "malas" decisiones. En ambos supuestos, el cuerpo propio permanecía siendo un bien indisponible e igualmente sucedía con la salud, bien contra el cual no se podía atentar a menos que se esgrimiera que la beneficiada final sería la salud misma. A la vez, eran terceras personas, independientes del beneficiario directo, las que determinaban cuándo el caso ameritaba una solución excepcional. Si el interesado directo era capaz de convencer con razones a juntas de expertos en cuestiones médicas, bioéticas y jurídicas, entonces podía ser habilitado para disponer de su función generativa; en caso contrario, su posibilidad de ejercer soberanía sobre su propio cuerpo se disipaba(3).

Los textos legales de las provincias citadas excedieron estas disputas y no repararon en sutilezas para, conservando la posición doctrinaria de la indisponibilidad corporal, permitir aquello que en principio se consideraba prohibido. Adoptaron la perspectiva más extrema y defendieron las prácticas esterilizantes desde el punto de vista de los derechos reproductivos y sexuales, adoptando una orientación claramente autonomista en la cual la disposición del cuerpo propio no estaba interdicta (señalamos aquí tan sólo las tendencias dominantes)(4).

Este proceso estuvo acompañado por otros fenómenos poco valiosos. Por ejemplo, se popularizó el turismo de remodelación sexual, desde regiones sin legislación hacia las provincias mencionadas, buscando satisfacción para las demandas más íntimas. ¿Podrían saldarse desigualdades de este tenor y homogeneizar los textos de leyes provinciales muy diversas legislando una norma para todos? Este expediente se consagró en agosto de 2006, cuando se sancionó la Ley Nacional 26.130 sobre el "Régimen para las intervenciones de contracepción quirúrgica", aprobada por el Congreso de la Nación Argentina ${ }^{2}$. A continuación, revisaremos su articulado, subrayando algunas deficiencias y señalando aspectos que deberían ser incluidos en una pronta reglamentación.

2 En un anexo se reproduce la Ley 26130-2006 y el Decreto 1110-2006 respectivo. 


\section{Ley argentina de contracepción quirúrgica humana: consideraciones de aplicabilidad}

El primer artículo de la ley consagra el derecho de toda persona mayor de edad a acceder a la realización de las prácticas denominadas "ligadura de trompas de Falopio" y "ligadura de conductos deferentes o vasectomía" en los servicios del sistema estatal y privado de salud. El motivo alegado es netamente contraceptivo, quedando de lado cualquier motivación terapéutica para justificar la elección del interesado por el método quirúrgico permanente. La actual legislación se apoya en una visión más moderna y acorde con la tendencia dominante en el plano mundial.

El segundo artículo establece tres requisitos necesarios para que una persona pueda solicitar para sí la práctica de contracepción quirúrgica: mayoría de edad, capacidad y consentimiento informado. Además, aclara que no será necesario solicitar el consentimiento del cónyuge o conviviente ni una autorización judicial.

Resulta acertado hacer coincidir la edad mínima de los peticionantes con el momento en que se alcanza la mayoría de edad para la legislación argentina (21 ańos), desechando una posible esterilización de menores de edad.

Sería deseable que la futura reglamentación tomara en consideración no sólo la capacidad jurídica del peticionante sino también su competencia moral, la forma madura en que participa del proceso de toma de decisiones médicas y ejerce genuinamente su autonomía (la escala de valores que fundamentan su opción, su habilidad para comprender y comunicar información, su capacidad para razonar y discutir acerca de la elección realizada y de los caminos alternativos disponibles, entre otros aspectos).

A nuestro parecer, sigue siendo conveniente informar a la pareja estable del solicitante sobre la decisión del compañero, al solo efecto de que tome conocimiento de la práctica y de sus consecuencias previsibles, pues se verá alterado su proyecto de vida familiar.

La no exigencia de una autorización o venia judicial que habilite la concreción de estos actos médicos esterilizantes constituye quizás el aporte más significativo de la ley. Por mucho tiempo, y a causa de una normativa legal insuficiente, poco clara y poblada de términos imprecisos, tuvo lugar una creciente judicialización de la relación médico-paciente para la realización de esterilizaciones humanas en Argentina. Este procedimiento, que se volvió habitual, perjudicó al solicitante de la intervención, al médico encargado de realizarla y al propio aparato jurisdiccional.

El tercer artículo de la Ley está dedicado a la situación de las personas declaradas judicialmente incapaces (donde la voluntad puede estar ausente), en cuyo caso torna requisito ineludible la autorización judicial solicitada por su representante legal antes de proceder a cualquier tipo de esterilización. Sabio recaudo procesal que opera como garantía contra abusos, a los que, de seguro, la reglamentación de la norma sumará otros: ¿qué jueces serán competentes para autorizar la esterilización? ¿Quién representará al incapaz en el proceso? ¿Cuáles son los plazos para la práctica de las actuaciones judiciales? ¿Cómo opera la resolución del procedimiento y cuáles son los medios de impugnación (recursos)? Son todos ellos requisitos de tipo procesal o procedimental.

Ahora bien, ¿qué ocurre con otros requisitos sustantivos? ¿Qué trámite se seguirá con una persona incapaz de hecho -es decir, que carece de capacidad natural de juicio o que tiene sus facultades mentales disminuidas-, que no cuenta con una declaración judicial de incapacidad pero que solicita la práctica biomédica para sí? ¿La norma se refiere a personas que adolecen de graves deficiencias psíquicas o también el legislador pensó en las deficiencias mentales leves y moderadas, e incluso en deficiencias de carácter físico que también pueden llevar a una incapacitación? ¿Cuál es el criterio de actuación que se debe privilegiar: el mayor beneficio o mejor interés y bienestar del incapaz o bien distintas consideraciones de orden económico, social y político, en atención al mundo adulto y sano? ¿¿Será necesario recurrir al dictamen de uno o más especialistas para constatar la existencia de aquella deficiencia alegada y la determinación de su gravedad, su permanencia e irreversibilidad, la comprensión del significado de la sexualidad y de la procreación y la capacidad para desempeñar correctamente la maternidad/paternidad por parte del presunto beneficiario, así como de la oportunidad de adoptar la medida esterilizadora y de sus consecuencias antes de formarse una decisión judicial? ¿Merecerá el beneficiario de la medida una exploración previa por parte del juez que intervenga en el caso, tendiente a valorar la apreciación y entendimiento, las capacidades cognitivas remanentes, la voluntad real y el verdadero consentimiento del incapaz, más allá de la 
aportación teórica de los dictámenes o de la audiencia preliminar? La legislación mencionada resulta pobre para responder a estos interrogantes básicos, puesto que ni siquiera los ha considerado(5).

El cuarto artículo se refiere a recaudos que acompañan al consentimiento informado y determina que el profesional médico interviniente, en forma individual o junto con un equipo interdisciplinario, debe informar a la persona que solicite la práctica sobre una serie de cuestiones atinentes a la intervención misma (naturaleza e implicancias sobre la salud, alternativas de utilización de otros anticonceptivos no quirúrgicos autorizados, características de la operación, posibilidades de reversión, riesgos y consecuencias, entre otros). Asimismo, estipula que deberá dejarse constancia en la historia clínica de haber proporcionado dicha información en términos comprensibles, y solicita que la persona conforme el proceso con su firma.

Con el avance de las técnicas microquirúrgicas, la esterilización humana se ha convertido en práctica de efectos permanentes con un grado estrecho de reversibilidad, condicionado por la técnica empleada en el quirófano (los conductos pueden ser cortados o seccionados, atados, cauterizados u obstruidos) y el tiempo transcurrido entre la intervención contraceptiva y la nueva cirugía de recanalización, por el estado de salud de los órganos reproductores del paciente y por su edad(6). Cuando se utilizan técnicas quirúrgicas modernas, la posibilidad de una reversión de la práctica con cierto grado de éxito es ocasional y nunca alcanza a la totalidad de los pacientes intervenidos. Y aunque pueda lograrse una exitosa recanalización o repermeabilización de sus conductos, ello no significa una futura concepción por vía natural. La realización de una intervención quirúrgica para recanalizar no es actualmente solventada por el Estado ni por las obras sociales o prepagas, y puede concluirse que la nueva ley tampoco ampara este tipo de cirugías reparadoras.

Este artículo alude también a la persona que suministrará información de calidad al sujeto interesado en la práctica. Según se expresa, el que lo haga será el profesional médico interviniente, ya sea en forma individual "o" juntamente con un equipo interdisciplinario. A nuestro entender, no parece adecuado que un solo profesional realice todo el proceso informativo, pues la íntima decisión acerca de la esterilización permanente implica una opción personalísima que no se reduce a la esfera médica, sino que involucra también otros aspectos sociales, culturales, emocionales, religiosos y psicológicos. En consecuencia, proponemos que el aporte interdisciplinario - conformado por profesionales de distintas áreas (médicos, psicólogos, trabajadores sociales) - no sea una mera posibilidad discrecional, sino que en todos los casos se asesore al paciente en forma colectiva -como parte de un proceso dialógico e intersubjetivamente mediado- y se evalúe la firmeza de la decisión tomada.

Queda establecido en la ley que el consentimiento informado del paciente debe ser otorgado previamente a la intervención quirúrgica; sin embargo, no se menciona un plazo temporal mínimo de antelación ni se determina el marco adecuado que permita una reflexión serena -para aclarar conceptos y despejar dudas- e, incluso, el arrepentimiento. La futura reglamentación tendría que habilitar un lapso suficiente entre el pedido esterilizante y su satisfacción.

Asimismo, no sería oportuno que el consentimiento fuera otorgado por pacientes embarazadas durante el tercer trimestre de su gestación ni, mucho menos, cuando apenas faltan unas horas para ser operadas vía cesárea. Este período no es el mejor momento para tomar una decisión de tal magnitud, debido a los cambios hormonales y de humor que inciden sobre la gestante. Diversos estudios han demostrado una íntima relación entre la toma de decisión esterilizante durante esta etapa y el mayor porcentaje de arrepentimientos, en años siguientes a la realización de la ligadura tubaria(7).

El quinto artículo trata sobre la cobertura de los costos de las intervenciones. Estas prácticas quirúrgicas serán realizadas sin cargo en los establecimientos del sistema público de salud e incorporadas a la cobertura por parte de las organizaciones de la seguridad social y las entidades de medicina prepaga, de modo tal que resulten totalmente gratuitas para los beneficiarios.

Pese a existir una ley nacional de salud reproductiva (Ley 25673-2002), que establece que los métodos anticonceptivos de carácter no permanente deben ser suministrados por las obras sociales y el sistema de salud pública, ésta aún no se cumple de manera uniforme en todas las regiones del país ni en todos los establecimientos. Esto conduce a los usuarios a pensar en los métodos permanentes como los más "económicos", puesto que resultan ser los únicos disponibles. De aquí la importancia que adquiere el cumplimiento de las disposiciones legales del Plan Médico Obligatorio 
y la provisión efectiva y gratuita de métodos de anticoncepción no permanentes como alternativa. Sólo de esta manera los pacientes que elijan la intervención esterilizante estarán ejerciendo su legítimo derecho de opción por el método anticonceptivo que consideren más adecuado.

El sexto artículo reconoce el derecho de objeción de conciencia para los profesionales de la salud, estableciendo que el personal médico o auxiliar del sistema sanitario puede negarse a llevar adelante las prácticas citadas, sin que ello pueda originarles consecuencia laboral alguna. Sin embargo, prevé que el ejercicio de este derecho no puede derivar en la privación de la práctica al peticionante, para lo cual las autoridades del establecimiento asistencial están obligadas a disponer los reemplazos necesarios.

Si bien la objeción es un derecho específico de la actividad médica y su ejercicio no exime de la responsabilidad institucional de garantizar el acceso a la práctica que estudiamos, el texto legislativo nada dice respecto del ámbito en el cual se hace uso del privilegio. Sería lógico exigir que los facultativos que son objetores de conciencia en el ámbito estatal, mantuvieran idéntica conducta en el ejercicio privado de su práctica, en el cual las esterilizaciones redundan en ingresos extraordinarios. En caso contrario, se estaría amparando la vigencia de un doble estándar ético.

La ley determina además que la objeción de conciencia no acarreará consecuencia laboral alguna para el profesional de la salud que se ampare en ella. No se comprende esta mención limitativa a la faz laboral, siendo que puede existir otra clase de consecuencias como las atinentes a la responsabilidad por daños. La futura reglamentación está obligada a echar luz sobre el asunto, con el fin de garantizar un efectivo ejercicio del derecho citado, que aleje la posibilidad de que los expertos se vean igualmente presionados a actuar por el habitual temor a una demanda por mala praxis.

El artículo 7 modifica el inciso 18 del artículo 20 de la ley 17.132 de "Ejercicio de la medicina, odontología y actividades de colaboración", relacionado con las acciones que quedan prohibidas para los profesionales del arte de curar. La ley 26.130 viene a determinar que el inciso 18 sea modificado de manera tal que, de ahora en más, quede prohibido a los médicos "practicar intervenciones que provoquen la imposibilidad de engendrar o concebir sin que medie el consentimiento informado del/de la paciente capaz y mayor de edad, o una autorización judicial cuando se trate de personas declaradas judicialmente incapaces". En otras palabras, bajo este nuevo régimen estará permitido practicar mencionadas intervenciones si media el consentimiento informado del paciente capaz y mayor de edad o bien una autorización judicial en el supuesto de las personas declaradas judicialmente incapaces.

Finalmente, el artículo 8 presenta un agregado al inciso b del artículo 6 de la ley 25.673 de "Creación del Programa Nacional de Salud Sexual y Procreación Responsable", en lo referido a los métodos y elementos anticonceptivos que deberán ser prescriptos y suministrados por los establecimientos de salud. Dispone que se aceptan como un método anticonceptivo más las prácticas de ligadura de trompas de Falopio y de ligadura de conductos deferentes o vasectomía, siempre que sean requeridas formalmente como método de planificación familiar y/o anticoncepción. Entonces, incorpora formalmente estos dos métodos permanentes de opción única.

\section{Conclusión}

Esta norma jurídica de eminente contenido bioético, surgida después de quince años de discusión entre distintos sectores sociales argentinos, permite a muchas personas satisfacer sus más íntimos deseos en el marco de la ley. Sin embargo, lastima pensar en un escenario en el cual todo el país dispone de un régimen "uniforme" que permite esterilizaciones quirúrgicas permanentes, mientras se continúa con un dispar acatamiento de la moderna legislación sobre salud reproductiva. Asusta también advertir que, probablemente, la única opción anticonceptiva y el único método de planificación familiar para los sectores populares en los efectores públicos y privados de salud pueda llegar a ser, en un futuro cercano, la esterilización permanente. Estos apuntes pretenden subrayar, una y otra vez, que la sola aparición de legislación sobre el particular -en ocasiones consecuencia de la aplicación de una racionalidad estratégica- abre un camino muy importante respecto de la planificación familiar y la programación de los hijos que desea tener una persona, pero no hace desaparecer aún los problemas éticos que le son afines. 


\section{Anexo}

Argentina, Ley 26.130 "Régimen para las intervenciones de contracepción quirúrgica” Sancionada 9-8-2006; Promulgada 28-8-2006; Publicada 29-8-2006.

El Senado y Cámara de Diputados de la Nación Argentina reunidos en Congreso, etc. sancionan con fuerza de Ley:

Art. 1. Objeto. Toda persona mayor de edad tiene derecho a acceder a la realización de las prácticas denominadas "ligadura de trompas de Falopio" y "ligadura de conductos deferentes o vasectomía" en los servicios del sistema de salud.

Art. 2. Requisitos. Las prácticas médicas referidas en el artículo anterior están autorizadas para toda persona capaz y mayor de edad que lo requiera formalmente, siendo requisito previo inexcusable que otorgue su consentimiento informado.

No se requiere consentimiento del cónyuge o conviviente ni autorización judicial, excepto en los casos contemplados por el artículo siguiente.

Art. 3. Excepción. Cuando se tratare de una persona declarada judicialmente incapaz, es requisito ineludible la autorización judicial solicitada por el representante legal de aquélla.

Art. 4. Consentimiento informado. El profesional médico interviniente, en forma individual o juntamente con un equipo interdisciplinario, debe informar a la persona que solicite una ligadura tubaria o una vasectomía sobre:

a) la naturaleza e implicancias sobre la salud de la práctica a realizar;

b) las alternativas de utilización de otros anticonceptivos no quirúrgicos autorizados, $y$

c) las características del procedimiento quirúrgico, sus posibilidades de reversión, sus riesgosy consecuencias.

Debe dejarse constancia en la historia clínica de haber proporcionado dicha información, debidamente conformada por la persona concerniente.

Art. 5. Cobertura. Las intervenciones de contracepción quirúrgica objeto de la presente ley deben ser realizadas sin cargo para el requirente en los establecimientos del sistema público de salud.

Los agentes de salud contemplados en la Ley 23.660, las organizaciones de la seguridad social y las entidades de medicina prepaga tienen la obligación de incorporar estas intervenciones médicas a su cobertura de modo tal que resulten totalmente gratuitas para el/la beneficiario/a.

Art. 6. Objeción de conciencia. Toda persona, ya sea médico/a o personal auxiliar del sistema de salud, tiene derecho a ejercer su objeción de conciencia sin consecuencia laboral alguna con respecto a las prácticas médicas enunciadas en el artículo $1^{\circ}$ de la presente ley.

La existencia de objetores de conciencia no exime de responsabilidad, respecto de la realización de las prácticas requeridas, a las autoridades del establecimiento asistencial que corresponda, quienes están obligados a disponer los reemplazos necesarios de manera inmediata.

Art. 7. Modifícase el inciso 18, del artículo 20, del capítulo I; del título II de la Ley 17.132 de régimen legal del ejercicio de la medicina, odontología y actividades auxiliares de las mismas, el que quedará redactado de la siguiente manera:

18: Practicar intervenciones que provoquen la imposibilidad de engendrar o concebir sin que medie el consentimiento informado del/la paciente capaz y mayor de edad o una autorización judicial cuando se tratase de personas declaradas judicialmente incapaces.

Art. 8. Agrégase al inciso b), del artículo $6^{\circ}$, de la Ley 25.673 de creación del Programa Nacional de Salud Sexual y Procreación Responsable, el siguiente texto:

Aceptándose además las prácticas denominadas ligadura de trompas de Falopio y ligadura de conductos deferentes o vasectomía, requeridas formalmente como método de planificación familiar y/o anticoncepción.

Art. 9. Comuníquese al Poder Ejecutivo.

Alberto Balestrini. - José J. B. Pampuro. - Enrique Hidalgo. - Juan H. Estrada.

Argentina, Decreto 1110-2006

Dado 28-8-2006; Publicado 29-8-2006

POR TANTO:

Téngase por Ley de la Nación No 26.130 cúmplase, comuníquese, publíquese, dése a la Dirección Nacional del Registro Oficial y archívese.

Néstor Kirchner. - Alberto A. Fernández. - Ginés M. González García. 


\section{Referencias}

1. Cecchetto S. Aspectos bioético-legales de la esterilización permanente en mujeres capaces e incapaces. Minoridad y Familia 2001; 15: 25-48.

2. Urbandt P. Esterilización femenina voluntaria en el hospital público. Mar del Plata: Suárez; 2002.

3. Cecchetto S. Vasectomía en los tribunales argentinos. Quirón 2003; 34(1-3): 125-134.

4. Urbandt P; Bostiancic MC. La esterilización femenina en el contexto de los derechos reproductivos. Mar del Plata: EUDEM; 2007.

5. Cecchetto S. La 'solución' quirúrgica. Derecho reproductivo y esterilización femenina permanente. Buenos Aires: Ad Hoc; 2004.

6. Hanafi M. Factors Affecting the Pregnancy Rate after Microsurgical Reversal of Tubal Ligation. Fertility and Sterility 2003; 80(2): 434-440.

7. Schmidt JE, Hillis SD, Marchbanks PA, et al. Requesting Information about and Obtaining Reversal after Tubal Sterilization: Findings from the U.S. Collaborative Review of Sterilization. Fertility and Sterility 2000; 74(5): 892898.

Recibido: 11 de junio de 2007.

Aceptado: 23 de julio de 2007. 